\title{
Delivery of blistered Medicines as an Important Factor in Medication Safety and Maintaining Patient Health in Times of Lockdown due to COVID-19
}

\author{
M. Herold (Mark Herold), E. Kalavsky (Erich Kalavsky)
}

St. Elisabeth University PhD Program and ARKAPO Center Munich, Germany. Original Article

\section{E-mail address:}

herold@arkapo.de

\section{Reprint address:}

Mark Herold

St. Elisabeth University PhD Program and ARKAPO Center Munich

FR Germany, Health Management

Munich

Germany

Source: Clinical Social Work and Health Intervention

Pages: $45-48$

Volume: 12

Issue: 2

\section{Reviewers:}

Steve Szydlowski

University of Scranton school of education, USA

Pawel S. Czarnecki

Rector of the Warsaw Management University, PL

\section{Keywords:}

Blistering. Packaging. Medication Safety. Lockdown. Covid-19.

\section{Publisher:}

International Society of Applied Preventive Medicine i-gap

CSWHI 2021; 12(2): 45 - 48; DOI: 10.22359/cswhi_12_2_08 CC Clinical Social Work and Health Intervention

\section{Abstract:}

The whole world is holding its breath and has fallen into a kind of paralysis of shock: the Corona pandemic is affecting the lives of every single person on Earth. Many have fallen ill, many have died, almost everyone is in lockdown. But everyday processes must continue, under special conditions, yet they must continue to function. Among them is the supply of medicines to the population. Here the question arises as to whether a higher level of medication safety, especially in a situation with an extremely stressed external environment, can be provided by blistering. In this context, it is relevant what exactly blistering means, which advantages and disadvantages are associated with it, for which reasons blistering is used and whether more safety for medication can be achieved through it. This is the subject of the following remarks. 
In December 2019, the first infections with a previously unknown virus became known in the Chinese city of Wuhan. ${ }^{1}$ This novel virus comes from the coronavirus family of viruses. It got its name from the summary of its lineage (coronaviruses) and the year of discovery (2019). The official name of the virus is SARS-CoV-2, the disease caused by the virus is called COVID-19. Here, SARS stands for „Severe Acute Respiratory Syndrome“ and COVID for „Corona Virus Disease". Due to the global impact and spread of COVID-19, this disease was declared a pandemic by the World Health Organization on 11 March 2020. If one considers only the current number of cases in Germany, COVID-19 can be described as an epidemic.

A variety of measures were taken to combat the pandemic in Germany, as in all other countries around the world. ${ }^{2}$ These measures are - depending on the infection event - differently pronounced, but in essence they all have the same goal: to reduce or even interrupt infection chains; to reduce the infection event; respectively the infection speed; thus to maintain the health care system and the care of the infected persons. Examples of measures taken to combat the Corona pandemic include the obligation to wear mouthnose protection, closures of individual industries and even the entire lockdown of German social life.

The Corona pandemic also has an impact on nursing homes and other medical facilities. The Robert Koch Institute has published special recommendations for the prevention and management of COVID-19 in old people's and nursing homes $^{3}$. These recommendations include both preventive and reactive measures related to Corona. First of all, it is relevant for the nursing homes to implement extended hygiene and infection control measures. This includes protective equipment and disinfection as well as waste disposal or the handling of laundry and other textiles. Of particular relevance in terms of prevention are all measures related to visitor regulations.
The Corona pandemic has thus created a particularly challenging and above all stressful situation in nursing homes. This exists both for the staff and for the patients and their (possibly also non-permitted) visitors. Nevertheless, medical care is relevant to the system and must be ensured without restriction even in these special situations. One possibility to increase safety in the dispensing of medicines is the so-called blistering, which is described in the following.

First of all, it must be explained what exactly is meant by the term blistering. „It can describe the pharmaceutical-technological process of primary packaging of a (usually solid oral) pharmaceutical form by temperature-regulated deepdrawing of a polyethylene (PE) or polypropylene film with the formation of blister cups and subsequent welding with a thin aluminum layer. Often, however, the „blistering“ of medicinal products by pharmacies in connection with home care will merely be a matter of ,portioning“ and packing various oral medicinal products previously removed from their original packaging and individually combined for individual patients into PE endless tubular bags. " ${ }^{\text {In }}$ the following, the term blistering is used exclusively for the repackaging and portioning of medicinal products.

A large number of framework conditions apply to blistering, which must be complied with to ensure the quality of the medicinal products. First of all, the legal framework conditions must be mentioned. ${ }^{5}$ Since blistering is a step in the manufacture of a medicinal product, the legal basis is the Medicines Act (germ. Arzneimittelgesetz (AMG)). Section 21 of the AMG stipulates that blistered medicinal products are exempt from the authorization requirement. This exemption from the authorization requirement is limited by the fact that it only applies to blistering in a pharmacy or on behalf of a pharmacy, according to the wording of the article ,for pharmacies“. „With the blistering of medicinal products taken from packages of various finished medici-

\footnotetext{
${ }^{1}$ Federal Ministry of Health (2020a), n.pag.

${ }^{2}$ Federal Ministry of Health (2020b), n.pag.

${ }^{3}$ Cf. Robert Koch Institut (2021), n. pag.

${ }^{4}$ Diebold/Schmidt (2007), p. 54.

${ }^{5}$ Diebold/Schmidt (2007), p. 54ff.
} 
nal products, a new medicinal product is created which is individually tailored to the individual patient on request or order [...]. ${ }^{6}$ In turn, $\S 12 \mathrm{a}$ of the AMG stipulates that the portioning and blistering of medicinal products individually for each patient on the premises of the pharmacy by appropriately trained staff within the framework of home care contracts does not require a license, as this task is part of the ,usual pharmacy operations". 7 The above-mentioned regulations are supplemented by $\S 6$ of the Pharmacy Operations Ordinance. According to this, a medicinal product manufactured in or by a pharmacy must be of a quality required by pharmaceutical science and must be manufactured and tested in accordance with recognized pharmaceutical rules. This also includes the indication of a usability date, whereby it must be noted that the expiry date originally dated by the original manufacturer or the pharmaceutical company refers exclusively to an original packaging that has not yet been manipulated. However, blistering changes this, so that a new expiry date must be defined. According to $\S 17$ of the Pharmacy Operations Regulation, only those medicinal products may be used for blistering which have been prescribed by a doctor for the individual patient or which have been approved for the German market as finished medicinal products. This regulation prevents pharmacies from procuring large quantities of preliminary stages of the finished medicinal product from the manufacturers in advance and blistering larger quantities from these. This would require a real manufacturing authorization according to the Medicines Act. Section 10 of the Pharmacy Act regulates that pharmacies may not exclusively commit themselves to certain original manufacturers or certain finished medicinal products when blistering. Another important legal framework for blistering is $\S 14$ of the Pharmacy Operations Regulation, which stipulates which labeling must be applied to the portioned and newly blistered medicinal products: Name, strength and batch designation of the medicinal product used, a date of usability, type of application or instructions for use, name and address of the pharmacy as well as name and address of the pharmaceutical manufacturers of the original finished medicinal products. There are further legal framework conditions which cannot be discussed due to the scope of this paper.

In addition to the legal framework conditions, there are other requirements for blistering. These include, first of all, spatial environmental conditions. ${ }^{8}$ Baumaterialien: Lighting, the room air conditioning system (humidity, temperature and general air supply) must be planned in such a way that adverse influences on the blistered medicinal products are avoided as far as possible. From a hygienic point of view, too, with regard to careful cleaning and disinfection, the room layout must be designed accordingly already in the planning phase, e.g. as few corners, edges and crevices as possible.

Furthermore, the equipment determines the possibilities of blistering. ${ }^{9}$ So-called blistering machines are used for this purpose. Different medicines are introduced into these machines by means of individual canisters. Chips and corresponding software are used to determine exactly which finished drug is available in which canister. The blistering is then triggered by a fully automatic process. It must be taken into account that the finished medicines used are exposed to a „fall“ from a certain height and must survive this without parts splintering off. It must also be taken into account that the canisters of the automatic blistering machines do not offer good protection of the finished medicinal products from external influences, so that they should not be stored in the canisters for too long.

There are also specifications for quality control, so that this also represents a framework condition of blistering that must be adhered to. ${ }^{10} \mathrm{As}$ soon as a quality control has been carried out, it must be documented. Despite the qualification of the machines and adequate validation of the software, malfunctions cannot be ruled out. After the

\footnotetext{
${ }^{6}$ Diebold/Schmidt (2007), p. 55.

${ }^{7}$ Diebold/Schmidt (2007), p. $55 \mathrm{ff}$.

${ }^{8}$ Riesenberger (2007), p. 46.

${ }^{9}$ Riesenberger (2007), p. 49.

${ }^{10}$ Riesenberger (2007), p. 52.
} 
quality control has been carried out and documented, a release of the manufactured medicinal product must be issued by the holder of the pharmacy operating license.

A particularly important aspect in the blistering of medicinal products is hygiene..$^{11}$ All surfaces, equipment, materials and media that come into contact with the finished medicinal products must be integrated into a special cleaning process. First of all, cross-contamination of the medicinal products is to be prevented, but the special hygiene also serves the blistering staff and, above all, the protection of the patients. The area where blistering takes place must be separated from the rest of the premises by a lock. The staff must be hygienically dressed or equipped, e.g. gloves, hygienic suits, etc.

Patient-specific blistering is therefore not a new measure that has arisen from the special situation surrounding the corona virus, but has already existed for many years and the legal and other framework for blistering is basically very strictly defined. The question arises whether blistering can create additional safety in medical care.

The patient-specific packaging of medicines initially improves patients' compliance. ${ }^{12}$ If adherence is reduced, this can lead to increased morbidity and mortality. In this respect, blistering is a mitigating measure. Furthermore, blistering can also lead to an increase in drug therapy safety for patients at risk. Particularly in the case of high-risk patients, the risks of wrong dosage or wrong times of administration occur more frequently, so that this risk can also be counteracted by means of blistering. The patient group of elderly, chronically ill citizens, who often live in nursing homes, particularly benefits from higher safety through blistering. ${ }^{13}$ These patients are often prescribed a higher number of medicines to be taken at the same time and thus have a higher check for interactions and side effects due to blistering.

The many framework conditions for blistering described above ensure that trained staff create individually tailored blisters for each patient under the best possible conditions and label them carefully. For patients, this is always - not only in times of a pandemic - a helpful solution and a risk reduction in everyday medication. For the staff in German nursing homes, blistering can initially mean a saving of time, but above all a reduction of the task budget. In concrete terms, a particularly relevant task is eliminated, leaving more time and concentration for the preventive and reactive handling of the Corona pandemic. A special side effect of blistering is the reduction of contact points and thus possible contamination points. In corona times, blistering means a real win-win situation for all involved.

\section{References}

1. FEDERAL MINISTRY OF HEALTH (2020A). General information on coronavirus, https://www.zusammengegencorona.de/informieren/basiswissen-zum-coronavirus/allgemeine-informationen-zum-coronavirus/ ; Stand: 17.02.2021.

2. RADI F, BUDZELOVA K, OLAH M, MUSS C (2021) Late psychosocial consequencesfrom HIV to Covid. Clin Soc Work and Health Interv.12.2021.2.6-7.10.22359/cswhi_12_2_15.

3. DIEBOLD S, SCHMIDT M (2007) Patientspecific blistering, in: German Pharmacist Newspaper, Issue 35/2007, S. 54-60.

4. LAUFS U et al (2011) Strategies to improve adherence to medication, in: German Medical Weekly, Heft 136, S. 1616-1621.

5. LAUTERBACH K et al (2006) Effects of the use of individual blisters on the costs and quality of drug therapy.

6. RIESENBERGER M (2007) Patients' individual second blistering, in: German Pharmacist Newspaper, Issue 48/2007, pp. 48-54.

7. ROBERT KOCH INSTITUT (2021) Prevention and management of COVID-19 in old people's and nursing homes and facilities for people with impairments and disabilities, https://www.rki.de/DE/Content/InfAZ/N/Neua rtiges_Coronavirus/Alten_Pflegeeinrichtung_Empfehlung.pdf?_blob=publicationFile ; Status 18.02.2021.

\footnotetext{
${ }^{11}$ Riesenberger (2007), p. 53.

${ }^{12}$ Laufs et al (2011), p. 1620.

${ }^{13}$ Cf. Lauterbach et al (2006), p. 7.
} 